\title{
Nikola Tesla, un genio entre luces y desfalcos (reseña descriptiva)
}

\section{Nikola Tesla, a genius among lights and embezzlements (descriptive review)}

Claudia P. Mejia V.

DOI: 10.29151/reit.n1a5 


\section{Resumen}

Nikola Tesla fue un gran científico e inventor que vivió entre mediados del siglo XIX y mediados del siglo XX. No solo se caracterizó por ser un personaje polémico, sino que también fue un gran visionario que cambió la forma en que aún hoy, nos comunicamos e interactuamos con el mundo. Entre sus contribuciones más importantes (inventos, adaptaciones y/o perfeccionamiento de equipos) están, el motor de corriente alterna, el manejo teledirigido de dispositivos, el transformador, la propulsión eléctrica, el generador de rayos $\mathrm{x}$, las bombillas fluorescentes, las luces de neón y de arco voltaico y los principios de la tomografía usada hoy en día para detección del cáncer. Si Nikola Tesla hubiese nacido en nuestro tiempo, muy seguramente habría tenido diagnóstico de esquizofrenia o de trastorno obsesivo compulsivo debido a su comportamiento excéntrico y a las frecuentes visiones vívidas que manifestaba tener.

Palabras clave: Nikola Tesla; motor de corriente alterna; radar. 


\section{Abstract}

Nikola Tesla was a great scientist and inventor who lived between the mid-19th and mid-20th centuries. He was characterized by being a controversial character and a great visionary who changed the way that even today, we communicate and interact with the world. Among his most important contributions (inventions, adaptations and /or improvement of equipment) are, the alternating current motor, the remote control of devices, the transformer, the electric propulsion, the $\mathrm{x}$-ray generator, the fluorescent bulbs, the radar, the lights of neon and arc flash and the principles of tomography used today for cancer detection. If Nikola Tesla would live in our time, he would most likely have been diagnosed with schizophrenia or obsessive-compulsive disorder due to his eccentric behavior and the frequent intense visions of that he manifested as having.

Keywords: Nikola Tesla; AC motor; radar. 


\section{Introducción}

En el libro "Nikola Tesla el genio al que le robaron la luz," se hace un recorrido por todos los aspectos de la vida y obra del gran inventor, a quien le debemos muchos de los desarrollos tecnológicos que se ven en la actualidad. Este libro, impreso en el 2009, es la versión en español de "Tesla Man out time" escrito en 1981 por Margaret Cheney. La versión en español de este libro, está compuesta por 29 capítulos (reseñados en la tabla 1) y 396 páginas.

Tabla 1. Relación de capítulos del libro "Nikola Tesla, El genio al que le robaron la luz"

\begin{tabular}{|c|c|c|c|}
\hline CAP. & NOMBRE & CAP. & NOMBRE \\
\hline 1 & UN MODERNO PROMETEO & 16 & $\begin{array}{l}\text { RIDICULIZADO, CONDENADO, } \\
\text { VILIPENDIADO }\end{array}$ \\
\hline 2 & EL JUGADOR & 17 & LA GRAN POLÉMICA DE LA RADIO \\
\hline 3 & INMIGRANTES DE POSTÍN & 18 & DIFICULTADES Y MADUREZ \\
\hline 4 & EN LA CORTE DEL SEÑOR EDISON & 19 & EL ASUNTO DEL NOBEL \\
\hline 5 & $\begin{array}{l}\text { EMPIEZA LA GUERRA DE LAS } \\
\text { CORRIENTES }\end{array}$ & 20 & EL HORNO VOLADOR \\
\hline 6 & $\begin{array}{l}\text { LA ORDEN DE } \\
\text { FLAMÍGERA }\end{array}$ & 21 & RADAR \\
\hline 7 & RADIO & 22 & EL INVITADO DE HONOR \\
\hline 8 & ALTA SOCIEDAD & 23 & PALOMAS \\
\hline 9 & HORAS ALTAS, HORAS BAJAS & 24 & TRÁNSITOS \\
\hline 10 & UN ERROR DE CÁLCULO & 25 & FIESTAS DE CUMPLEAÑOS \\
\hline 11 & RUMBO A MARTE & 26 & CORCHOS A LA DERIVA \\
\hline 12 & AUTÓMATAS & 27 & COMUNIÓN CÓSMICA \\
\hline 13 & EL HACEDOR DE RAYOS & 28 & MUERTE Y TRANSFIGURACIÓN \\
\hline 14 & APAGÓN EN COLORADO SPRINGS & 29 & LOS PAPELES PERDIDOS \\
\hline 15 & ENSALZADO Y HUMILLADO & & \\
\hline
\end{tabular}

Margaret Cheney es una escritora norteamericana nacida en 1921 y destacada biógrafa que también escribió junto con Robert Uth "Tesla: Master of Lightning" que va en la misma temática de este inventor y científico.

Volviendo al libro de nuestro interés, en los dos primeros capítulos se abordan aspectos de su infancia, juventud y asuntos de índole familiar. Los capítulos tres al doce, tratan temas relacionados con su vida laboral y los engaños que tuvo que encarar debido a su tal vez idealizada y un poco 
ingenua visión del mundo. En esta parte también se habla de la desleal competencia ejercida por parte de su antiguo jefe Edison con el fin de desacreditar su modelo de corriente alterna. Del capítulo 13 al 16, se habla de algunos de sus proyectos fallidos ya sea por falta de financiación o que por estar fuera de su tiempo no era posible su construcción. Del capítulo 17 al 29, con un Tesla más maduro y menos ingenuo (razón por la que empezó a patentar todas sus creaciones teniendo en cuenta los sinsabores vividos en experiencias previas), se habla de otros inventos y la polémica acerca de la invención de la radio con Marconi, ya que este último usó sin permiso patentes de Tesla para su construcción. Hacia el final de su vida, sus excentricidades fueron en aumento, al punto de desarrollar un amor por las palomas a las cuales alimentaba y cuidaba con un esmero que rayaba en lo enfermizo. Nikola Tesla murió de un infarto en Nueva York el 7 de enero de 1943 en la habitación del hotel en la que vivía. Murió arruinado, solo y olvidado por la mayoría.

Como se puede esbozar, el libro no se limita a hacer un recorrido biográfico del inventor en cuanto a lo profesional y/o científico, sino que también ahonda en aspectos cotidianos de su vida, sus excentricidades, sus concepciones del mundo y sus desfalcos.

\section{Abordaje del contenido del libro}

Nikola Tesla nació en Croacia, a la media noche del 9 al 10 de julio de 1856. Su padre, sacerdote ortodoxo, vivía con su esposa e hijos (2 hombres y 3 mujeres incluyendo a Tesla que era el cuarto), en una casa al lado de la parroquia que atendía. Era una familia que, aunque no tenía lujos, no pasaba necesidades.

El contexto de la época en la región que habitaba Tesla no daba muchas opciones profesionales más que ser labriego, militar o clérigo. De hecho, la mayoría de familiares de Tesla, eran militares o clérigos, o en el caso de las mujeres, se habían casado con alguno de ellos. Su padre Milutín Tesla, consideraba que el mejor futuro para sus hijos estaba en abrazar la vida eclesial. En cuanto a la madre de Tesla, era una mujer muy inteligente con una memoria prodigiosa que le permitía recitar repertorios completos de poesía, sin embargo, para la época, tales cualidades no se preciaban en una mujer. Crecer en un hogar lleno de citas bíblicas y poesía dio pie para que, en su juventud y muy de vez en cuando durante el resto de su vida, Nikola también escribiera versos, aunque nunca consintió en publicarlos. De todas maneras, de mayor animaba sus tertulias privadas recitando poemas de su país de origen (en inglés, francés, alemán o italiano).

Su carisma como inventor se manifestó desde muy niño cuando a los cinco años, construyó una rueda hidráulica propia, lisa y carente de paletas que giraba al paso del agua como las demás. También le gustaba desarmar y armar los relojes de su abuelo. Después recordaría lo poco que le había durado aquella afición: "Siempre concluía con éxito la primera operación, pero no solía atinar en la segunda". La muerte de su hermano Daniel, siete años mayor que él y ocurrida cuando Tesla contaba con cinco años afectó profundamente su carácter, y le hizo sentir desde joven la necesidad de mitigar el dolor de sus padres. Según su propio testimonio, desde pequeño decidió someterse a una férrea disciplina para sobresalir en todo; trataba de ser más austero, más generoso y estudioso que sus compañeros, sacándoles ventaja en todos los campos, con el fin de no darle motivo de angustia a sus padres. Desde la muerte de su hermano la percepción de Tesla, es que todo lo que él hiciera quedaba empañado por el recuerdo del prometedor hermano fallecido. Sus propios logros según sus palabras "sólo servían como pretexto para que mis padres lamentasen aún más su pérdida. De modo que, si bien nadie pensaba de mí que fuera tonto, no desarrollé una gran confianza en mí mismo durante la infancia...". Se cuenta también que, desde muy pequeño, sentía molestos fogonazos de luz que le cegaban y no 
solo distorsionaban la realidad, sino que tampoco le permitían pensar con claridad. De igual manera desde su infancia mostró una imaginación rica y vivaz.

En su juventud, su vocación para la ingeniería se fue afianzando con fuerza y en los estudios destacaba en las matemáticas y los idiomas. Sin embargo, tuvo muchos problemas de salud que lo IIevaron casi a la muerte. En uno de estos periodos de convalecencia, le pidió a su padre que le dispensara de aspirar a la vida clerical y le permitiera estudiar ingeniería, a lo cual él accedió. De esta forma, en 1875 se matriculó en la Escuela Politécnica Austríaca de Graz. Estudió becado por la sociedad de las autoridades militares de fronteras y no pasó ningún apuro económico hasta que dicha sociedad se disolvió. Su férrea disciplina lo motivaba a estudiar desde las tres de la mañana hasta las once de la noche con la intención de sacar adelante los cursos en la mitad de tiempo. Física, matemáticas y mecánica fueron las asignaturas a las que más se dedicó. Dado los altos costes educativos y al no contar con beca, a partir del segundo año comenzó a buscar dinero para complementar su sustento en las apuestas con juegos de azar, cartas y billar, convirtiéndose en ludópata. Al final, terminó abandonando los estudios. Sin embargo, a partir de ahí comenzó a pensar en la posibilidad de diseñar motores eléctricos más eficientes que condujeron en la creación del motor de corriente alterna. Con el tiempo, consiguió superar su adicción al juego, así como otros malos hábitos que le fueron apareciendo,-fumar y tomar café en exceso- usando su fuerza de voluntad que cultivó a través de su vida.

Luego de haber sido oyente en algunas universidades y estudiar con ahínco de manera autónoma llegando a ser considerado autodidacta por muchos, se vinculó al mercado laboral en 1881 gracias a la ayuda de un tío que le consiguió trabajo en Budapest. En esta época, con los sentidos acuciadamente desarrollados, y en medio de una fuerte crisis nerviosa que curó con ejercicio físico y largas caminatas, Tesla logró diseñar el motor de corriente alterna. Un invento que al mundo le tomaría años darle su debida importancia.

En 1882, sin tiempo ni dinero para diseñar más inventos y con las ideas burbujeando en su mente, se concentró en su trabajo donde no en poco tiempo ascendió a la categoría de Ingeniero, adquiriendo experiencia y haciendo muchas mejoras en los equipos de la empresa en que trabajaba. Por recomendación laboral de familiares, luego de su estancia en Budapest se trasladó a la filial telefónica de Edison en París, donde tenía planeado vender los planos de su invento del motor y mostrar los enormes beneficios potenciales de la corriente alterna. Sin embargo, se llevó una profunda decepción al saber que Edison hacía oídos sordos a esta posibilidad. No obstante, habiéndose ganado el favor del director de la empresa en París, se dejó convencer por él de trasladase a Estados Unidos.

Ya en New York y trabajando para Edison, se dio cuenta que Edison era un hombre mordaz y no tenía reparos éticos a la hora de ganar dinero. Solía pronunciar frases lapidarias como "En el comercio y en la industria, todo el mundo roba, hasta yo mismo he robado, Pero, al contrario que los demás, yo sé cómo hacerlo", "Un hombre siempre hace las cosas guiado por dos motivos: uno bueno, y otro, que es el verdadero". También gustaba de afirmar que reconocía la importancia de sus inventos por los dólares que lograba facturar, lo demás le importaba poco.

Edison no tardó en reconocer la valía de Tesla y su consagración al trabajo por las muchas mejoras que hizo a los equipos de su empresa. Sin embargo, por no pagarle la suma de 50.000 dólares, acordada por unas mejoras que desarrolló Tesla en los rudimentarios dínamos de Edison, Tesla terminó renunciando. Luego de salir de la empresa de Edison intentó crear su propia empresa, pero de nuevo las "formas norteamericanas de hacer negocios" lo dejarían en la ruina y buscando tra- 
bajo como cualquier obrero. En esa época de su vida, apenas conseguía llegar al día siguiente en lo económico, a pesar de que su reputación como ingeniero iba en aumento.

Luego de una espectacular conferencia dictada el 16 de mayo de 1888, titulada "Un nuevo sistema para motores y transformadores de corriente alterna" consiguió que el empresario Westinghouse le contratase como asesor en su empresa para adaptar su sistema monofásico, a cambio de un salario de dos mil dólares mensuales. Aquellos ingresos extra le venían de perlas, pero le obligaban a trasladarse a Pittsburgh y dejar New York. Tesla y Westinghouse llegaron a un acuerdo para desarrollar el sistema de corriente alterna; cuando Edison se enteró, sintiendo amenazado su monopolio, comenzó a hacer propaganda desacreditando dicho sistema. Sin embargo, el tiempo hizo justicia con Tesla y le dio la razón, siendo el sistema de transmisión de corriente alterna empleado hoy en día. (Esta época es la que se conoce como de la guerra de las corrientes).

Con el paso del tiempo y debido al coste económico que había supuesto para Westinghouse invertir en la carrera tecnológica a favor de la corriente alterna teniendo la campaña de Edison en contra, éste le pidió a Tesla que renunciase a recibir las ganancias a las que tenía derecho por la generación de electricidad con este método. En agradecimiento por haberle dado la mano en momentos difíciles, Tesla aceptó. Realmente NO fue una buena decisión haber renunciado a algo que en el futuro le habría generado buenos dividendos para llevar una vida holgada. Aquí es desfalcado de nuevo económicamente (la primera fue cuando Edison no le pagó la suma prometida por el perfeccionamiento de sus equipos).

Otro gran sueño de Tesla era transmitir la energía eléctrica de forma aérea sin usar cables, aprovechando la conductividad de la ionósfera, y con el fin de distribuirla gratuitamente para beneficio de todos. Para financiar este proyecto, recurrió a uno de los banqueros más poderosos de la época (J. P. Morgan) quien lo financió hasta cierto tope que resultó ser insuficiente dada las tasas de inflación de ese tiempo. La Wardenclyffe Tower-estructura principal del proyecto- quedó inconclusa, nunca llegó a funcionar del todo y finalmente fue derribada, terminando con Tesla endeudado.

Aún desanimado como estaba y sumido en la bancarrota, entre 1916 y 1920 corrigió y publicó los principios básicos de lo que, casi treinta años más tarde, se conocería como radar. Por esa época también comenzó su dedicación por las palomas que encontrase enfermas, a las que curaba de todo tipo de enfermedades, inclusive, pagando veterinario cuando no sabía la enfermedad que presentaban. En la década de los treinta comenzó a perder a quienes habrían sido sus aliados, su salud también se fue haciendo cada vez más endeble por los años y padeció algunos episodios de demencia.

Gracias a la fundación del Instituto Tesla en Belgrado, se recopiló información sobre sus primeros inventos con el consentimiento de Tesla. De esta manera, el Gobierno yugoslavo y algunos ciudadanos eslavos a título individual suscribieron un compromiso que le garantizaba a Tesla el cobro de un salario de siete mil doscientos dólares anuales. Gracias a sus compatriotas, "el inventor más genial de todos los tiempos" no se vio abandonado en los últimos años de su existencia.

\section{Conclusiones}

En cuanto al libro, es una recopilación bastante completa y enriquecedora de la vida de Tesla sobre todo en su aspecto como ser humano.

En cuanto al contenido, muestra cómo es la preparación de un ingeniero y científico. Esta formación está fundamentada en el trabajo duro, gran capacidad de aprendizaje autónomo y una férrea disciplina si se busca obtener importantes avances en la ciencia o la ingeniería 
independientemente del reconocimiento de sus contemporáneos.

Visualiza también que, en cuestión de negocios, no se puede ser confiado y se debe ser organizado con los gastos.

Se aprende también que muchos defectos se pueden corregir con fuerza de voluntad. El no corregirlos de manera rápida, conllevan a pérdida de tiempo, dinero y talento.

\section{Referencias}

Cheney, M. (2009). Nikola Tesla El genio al que le robaron la luz. Turner Noema. (Traducción).

Cheney, M. (1981). Tesla man out time. E.E.U.U. Prentice Hall.

Cheney, M., Uth R. (1999). Tesla: Master of Lightning. E.E.U.U. Barnes \& Noble Book 
FUNDACIÓN UNIVERSITARIA MONSERRATE - UNIMONSERRATE

Av. Calle $68 \mathrm{~N}^{\circ}$ 62-11

Bogotá - Colombia 